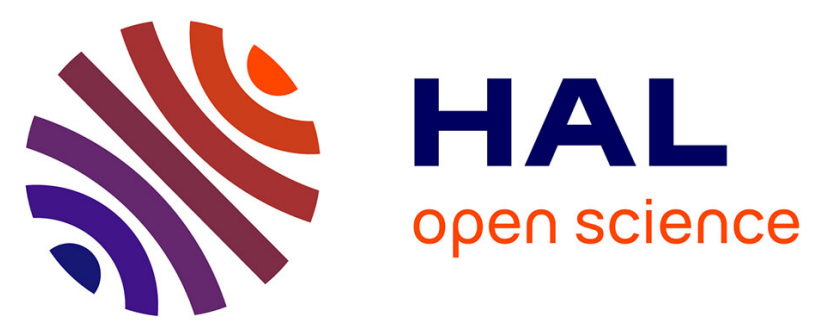

\title{
A Fuzzy-Based Approach for the Diagnosis of Fault Modes in a Voltage-Fed PWM Inverter Induction Motor Drive
}

Fatiha Zidani, Demba Diallo, Mohamed Benbouzid, Rachid Naït-Saïd

\section{- To cite this version:}

Fatiha Zidani, Demba Diallo, Mohamed Benbouzid, Rachid Naït-Saïd. A Fuzzy-Based Approach for the Diagnosis of Fault Modes in a Voltage-Fed PWM Inverter Induction Motor Drive. IEEE Transactions on Industrial Electronics, 2008, 55 (2), pp.586-596. 10.1109/TIE.2007.911951 . hal00524628

\section{HAL Id: hal-00524628 \\ https://hal.science/hal-00524628}

Submitted on 8 Oct 2010

HAL is a multi-disciplinary open access archive for the deposit and dissemination of scientific research documents, whether they are published or not. The documents may come from teaching and research institutions in France or abroad, or from public or private research centers.
L'archive ouverte pluridisciplinaire HAL, est destinée au dépôt et à la diffusion de documents scientifiques de niveau recherche, publiés ou non, émanant des établissements d'enseignement et de recherche français ou étrangers, des laboratoires publics ou privés. 


\title{
A Fuzzy-Based Approach for the Diagnosis of Fault Modes in a Voltage-Fed PWM Inverter Induction Motor Drive
}

\author{
Fatiha Zidani, Demba Diallo, Senior Member, IEEE, \\ Mohamed El Hachemi Benbouzid, Senior Member, IEEE, and Rachid Naït-Saïd
}

\begin{abstract}
This paper investigates the use of fuzzy logic for fault detection and diagnosis in a pulsewidth modulation voltage source inverter (PWM-VSI) induction motor drive. The proposed fuzzy technique requires the measurement of the output inverter currents to detect intermittent loss of firing pulses in the inverter power switches. For diagnosis purposes, a localization domain made with seven patterns is built with the stator Concordia current vector. One is dedicated to the healthy domain and the six others to each inverter power switch. The fuzzy bases of the proposed technique are extracted from the current analysis of the fault modes in the PWM-VSI. Experimental results on a $1.5-\mathrm{kW}$ induction motor drive are presented to demonstrate the effectiveness of the proposed fuzzy approach.
\end{abstract}

Index Terms-Concordia transform, diagnosis, fault detection, fuzzy logic, induction motor, voltage source inverter (VSI).

\section{INTRODUCTION}

$\mathbf{I}$ N MOST industrial applications, induction motors are predominantly fed from pulsewidth modulation voltage source inverter (PWM-VSI) for variables speed operation. Indeed, the most common drive in the industry is that with a VSI and induction motor. PWM-VSI induction motors are usually more reliable than those supplied directly online. For instance, the problem of broken rotor bars, mainly due to excessive starting torque, is practically avoided by means of soft starting with an inverter. However, the use of inverters has some drawbacks. Indeed, the introduction of power electronic converters came with an increased possibility of component failures. It is the power electronic stage of the drive, including its dc link and control circuitry, which becomes the system's weakest part in the sense of operational reliability. High costs due to standstill and repair, as well as the general need to improve

Manuscript received March 31, 2006; revised October 1, 2007. Paper presented at the 2005 IEEE International Electric Machines and Drives Conference, San Antonio, TX, May 15-18.

F. Zidani and R. Naït-Saïd are with the University of Batna, 05000 Batna, Algeria.

D. Diallo is with the Laboratoire de Génie Electrique de Paris, CNRS UMR 8507, Supélec; Université Pierre et Marie Curie P6; Université Paris Sud P11, 91192 Gif-Sur-Yvette, France (e-mail: ddiallo@ieee.org).

M. E. H. Benbouzid is with the Laboratoire d'Ingénierie Mécanique et Electrique, University of Western Brittany, Rue de Kergoat-CS 93837, 29239 Brest Cedex 03, France (e-mail: m.benbouzid@ieee.org).

Color versions of one or more of the figures in this paper are available online at http://ieeexplore.ieee.org.

Digital Object Identifier 10.1109/TIE.2007.911951 reliability, have led to research in fault detection, as surveyed in [1] and [2].

Within the drive, faults can occur in the machine or in the inverter.

While the induction motor diagnosis is abundantly investigated in the literature [3]-[8], failures of the inverter are not as well treated. In [9], the author studied the behavior of a PWMVSI induction motor under key fault types normally verified in industry applications. While a short circuit is the usual fault mode of power switches, an open circuit is another fault that can occur. Short circuit detection has become a standard feature of driver ICs. However, much fewer research results have been published on open circuit faults. An open switch fault can lead to overstresses on the healthy switches as well as to pulsating current. This can in turn lead to failures in other components, for example by causing a torque ripple in a drive fed by such an inverter.

For insulated-gate bipolar transistor (IGBT) open circuit faults, some basic research results are published. In [10], a methodology is presented to detect intermittent misfiring in a voltage-fed PWM-VSI induction-motor drive. The technique is based on the stator current time-domain response. In [11], the authors introduced two techniques to identify the voltagefed PWM inverter fault modes. The first one uses the analysis of the current-vector trajectory to identify fault modes. The second one determines the fault condition of the inverter from the current vector instantaneous frequency. In [12], the authors suggested using the average motor currents Park's vector monitoring for diagnosing voltage-fed inverter faults in ac drives. In [13], the control deviation, which occurs whenever the line currents cannot follow the reference, is used. In case of an open circuit fault, the control deviation calculated in $d-q$ components rises and falls periodically with the mains frequency. The maximum deviation provides information to localize the faulty switch. In [14], it is suggested to use the direct component of line currents. To obtain a diagnosis variable that is independent of the actual load, first-order harmonic coefficients of line currents are computed by means of a DFT. The above presented techniques have been analyzed and compared in [15]. All these suggested techniques take at least one fundamental period between the fault occurrence and the fault detection. Recently, in [16], techniques are proposed that require voltage measurements at the key point of the drive and are based on an analytical model of the VSI. The fault condition is in this 
case detected within one-fourth of the fundamental cycle. More recently, in [17], the PWM-VSI induction motor condition monitoring mechanism is based on discrete wavelet transform and fuzzy logic. The fault features are directly extracted from the wavelet transform of the stator currents. Finally, in [18], the authors use a centroid determination method. A centroid is a common analysis used primarily in material characterization. The Concordia pattern is central to the developed fault diagnosis technique. To determine the fault condition, an ideal Concordia transform centroid is compared to the actual Concordia Transform centroid. By calculating the centroid based upon only the positive values of $\alpha$ or $\beta$ axis, the differentiation between faults within the inverter is achieved. The centroid calculations are conducted on a per cycle basis.

Three methods are mainly used in fault detection and diagnosis: model-based techniques, expert systems, and artificial intelligence methods. Model-based techniques are very outstanding if an accurate model of the process can be obtained. In induction motor drives, an accurate model of the whole system is difficult to obtain. The inverter model (including snubber capacitance and balance resistors) is not only hard to obtain but also inaccurate due to component values, parasitic components, and unavoidable assumptions and limitations. Therefore, methods that do not require model knowledge are of great interest. Expert systems usually dedicated to big systems are useful if minor modifications are made in the process and above all assume the existence of an expert to build the rules and the reasoning tree [19]. The introduction of artificial intelligence methods (fuzzy logic and artificial neural network) is a step forward to more flexibility, as there is no need for a model but also no need for expert knowledge [20]-[24]. The accuracy of these methods depends upon the initial training data in healthy and faulty conditions. Nevertheless, this is not a major drawback in this case because reliable simulation tools exist that can furnish appropriate data.

This paper proposes a fuzzy technique to detect misfiring (intermittent loss of firing pulses) in the switches of a PWMVSI induction motor drive. Such a technique requires the measurement of the output inverter currents. Different from the above discussed technique, the proposed approach uses only two current sensors for simplicity and cost-effectiveness to build a seven pattern-localization domain made with the stator Concordia current vector. One is dedicated to the healthy domain and the six others to each inverter switch. The fuzzy bases of the proposed technique are extracted from the current analysis of the fault modes. With this technique, it is possible to detect and to identify the faulty switch. This paper is the followup of the one initiated in [24]. The topology of the examined inverter is given in Fig. 1. Only two current sensors are used and no mechanical one is considered.

\section{PWM-VSI POWER SWITCHES OPEN CiRCUIT/Misfiring DETECTION AND DiAGNosis}

Inverter power switch faults are subdivided into short circuit and open circuit. Short circuits, in most cases, cause an overcurrent detected by the standard protection system (e.g., input fuses, circuit breaker) and a shut down of the drive is carried

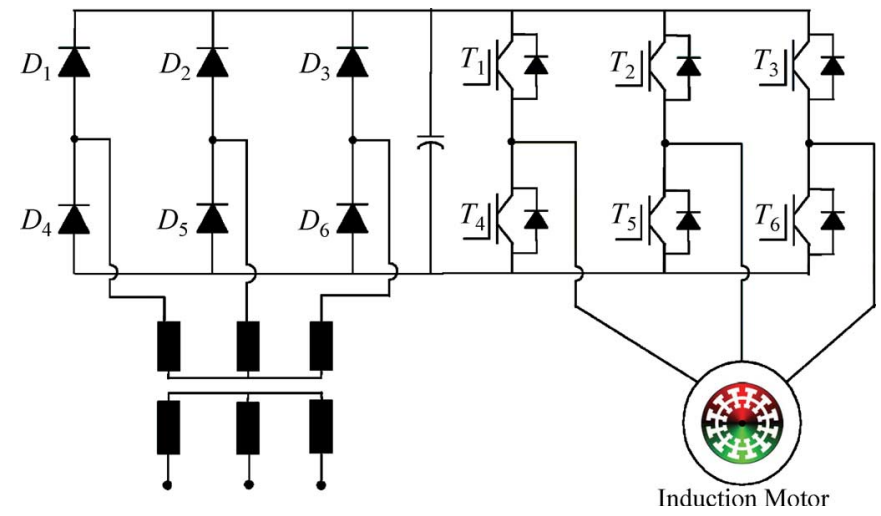

Fig. 1. VSI-fed induction motor.

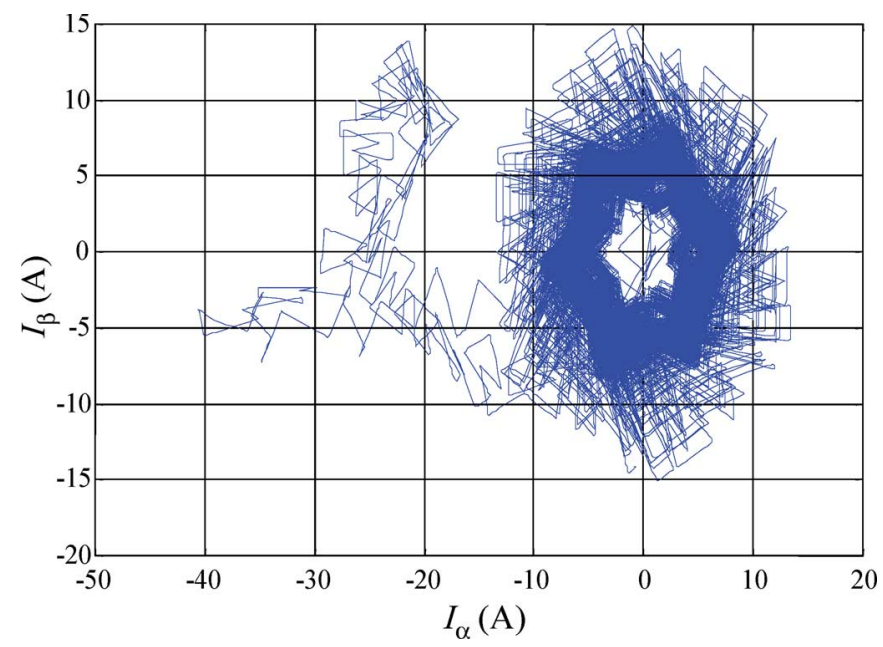

Fig. 2. Current pattern in case of $T_{1}$ misfiring.

out. Further operation is not possible and a repair is necessary. Standard protection schemes of inverter-fed motor drives are usually designed to prevent power switch damage.

Voltage source PWM inverters with an open power switch (due to misfiring) will show typical current patterns.

In this paper, the standard stationary reference frame $\alpha-\beta$ is used to evaluate the stator current pattern evolution when open circuit power switches occur in the inverter. In healthy and ideal conditions, the stator current pattern in the Concordia reference frame is a circle with a constant radius in steady state. When a fault occurs in the electronic circuit of a switching device leading to a misfiring, the stator current pattern is biased in such a direction that allows fault diagnosis. The asymmetry in the output voltage creates a dc component, which introduces in the sinusoidal current a dc component whose sign indicates the bias direction. Fig. 2 shows the simulated pattern in case of $T_{1}$ intermittent misfiring of $4 \mathrm{~ms}$ duration. Because of the PWM, the locus is obviously not a circle. The other patterns in case of misfiring are easily obtained by rotating the previous pattern of $120^{\circ}$. This fact is clearly illustrated by Fig. 3 where the vector current trajectory before and after $T_{2}$ misfiring is shown. Fig. 4 schematically summarizes current vector trajectories in faulty modes.

As illustrated by Fig. 4, in case of an open circuit, the current trajectory shows a typical fault pattern that is a semicircle. Its relative position characterizes the faulty switch. Therefore, for 


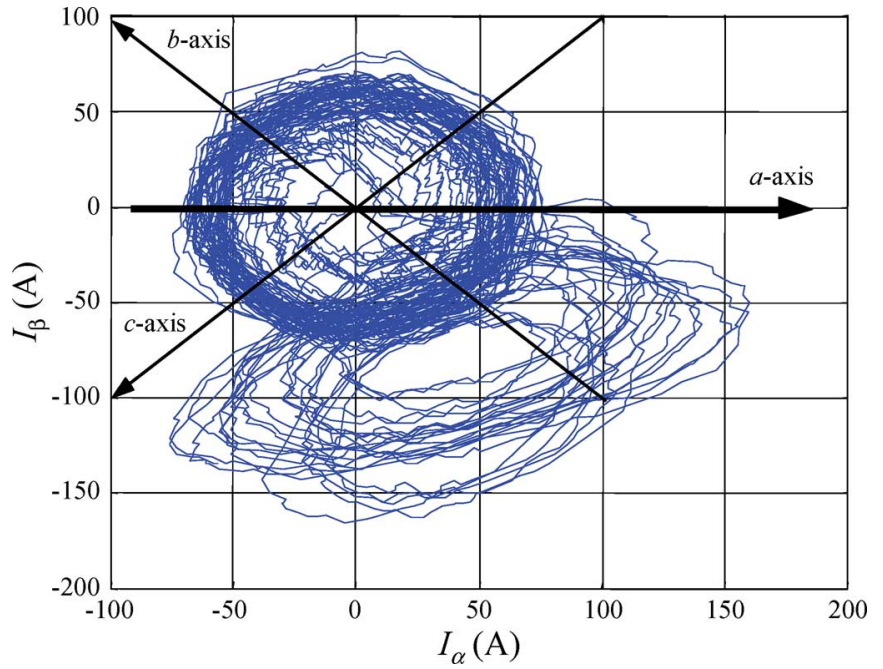

Fig. 3. Current pattern in case of $T_{2}$ misfiring during start-up.

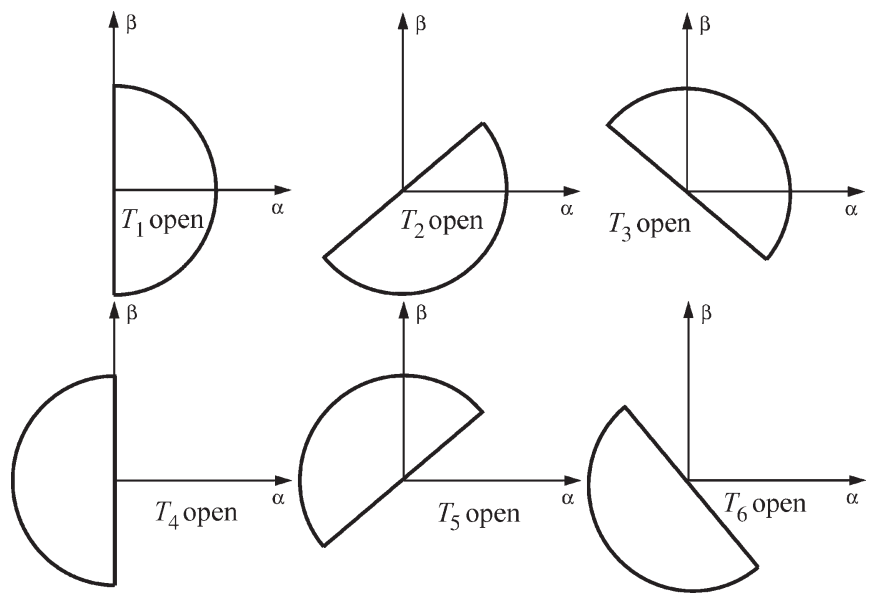

Fig. 4. Current patterns in faulty modes.

PWM-VSI power switches open circuit/misfiring detection and diagnosis, the proposed fuzzy approach will be based on the output inverter current pattern in the Concordia frame.

\section{FuZZy Diagnosis APPROACH}

The main reason for choosing a fuzzy approach is the very nature of the changes in the attributes. It is nonlinear, and in addition, it would be unreasonable to expect that each time the same level of a particular fault arises, the attributes would measure exactly the same values. The boundaries between two levels of a certain fault or between two faults are not sharply defined, and therefore the use of a classic true or false logic is inappropriate, whereas use of a fuzzy logic instead is highly justified. Membership functions and the degree of membership, rather than yes or no membership, give the opportunity, using previously acquired knowledge about the system attributes, to define and create a fuzzy rule-based system that can be used as a diagnosis tool to monitor the condition of the PWM-VSI [25], [26].

The fuzzy bases of the proposed approach are extracted from the analysis of the PWM-VSI fault modes as discussed in Section II. This analysis has led to a fault detection and di-

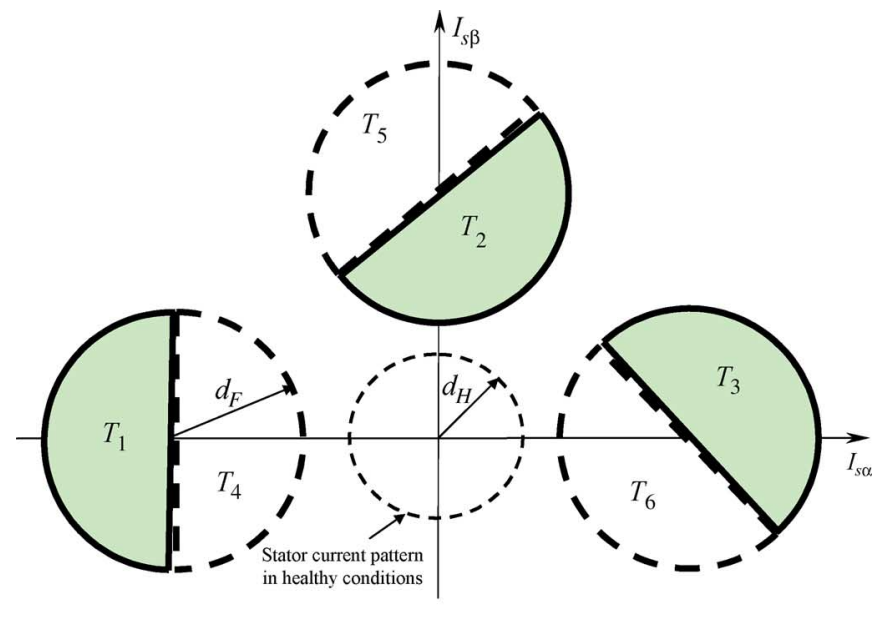

(a)

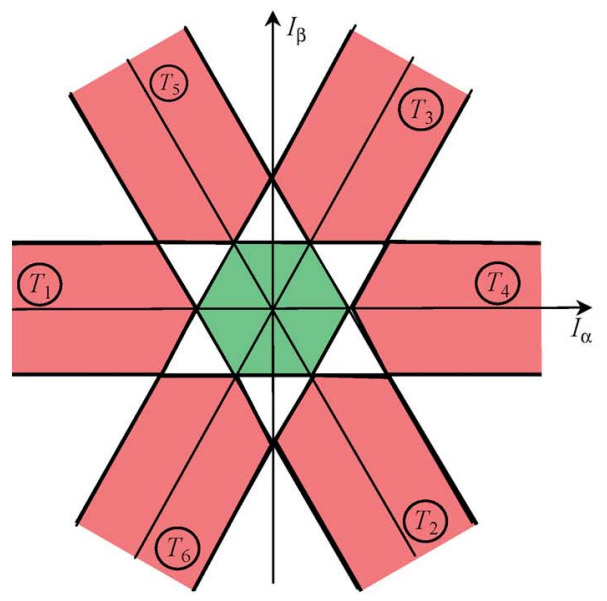

(b)

Fig. 5. Fault detection and diagnosis space. (a), (b) [24].

agnosis space shown by Fig. 5(a). For comparison purposes, Fig. 5(b) shows the diagnosis space used in [24]. Fig. 6 schematically summarizes the fuzzy logic based diagnosis approach where FFDD is the Fuzzy Fault Detection and Diagnosis block.

\section{A. Fuzzy Logic Diagnosis Reasoning}

The diagnosis procedure is based on the analytical and heuristic knowledge symptoms of the PWM-VSI behavior. Heuristic knowledge in the form of qualitative process models can be expressed as if-then rules. The task is achieved by a fault decision process which specifies the type, size and location of the fault as well as its time of detection. In this paper, analytical and heuristic symptoms are the error $E_{\mathrm{d}}$ between healthy and faulty current pattern diameters and an integer $I_{\theta}$ indicating the location of the stator current vector in the $\alpha-\beta$ reference frame $\left(\theta=\operatorname{angle}\left(I_{\mathrm{s} \alpha}, I_{\mathrm{s} \beta}\right)\right)$.

These two variables are the inputs of the FFDD block. $E_{\mathrm{d}}$ and $I_{\theta}$ are calculated as follows:

$$
E_{\mathrm{d}}=d_{\mathrm{H}}-d_{\mathrm{F}}
$$




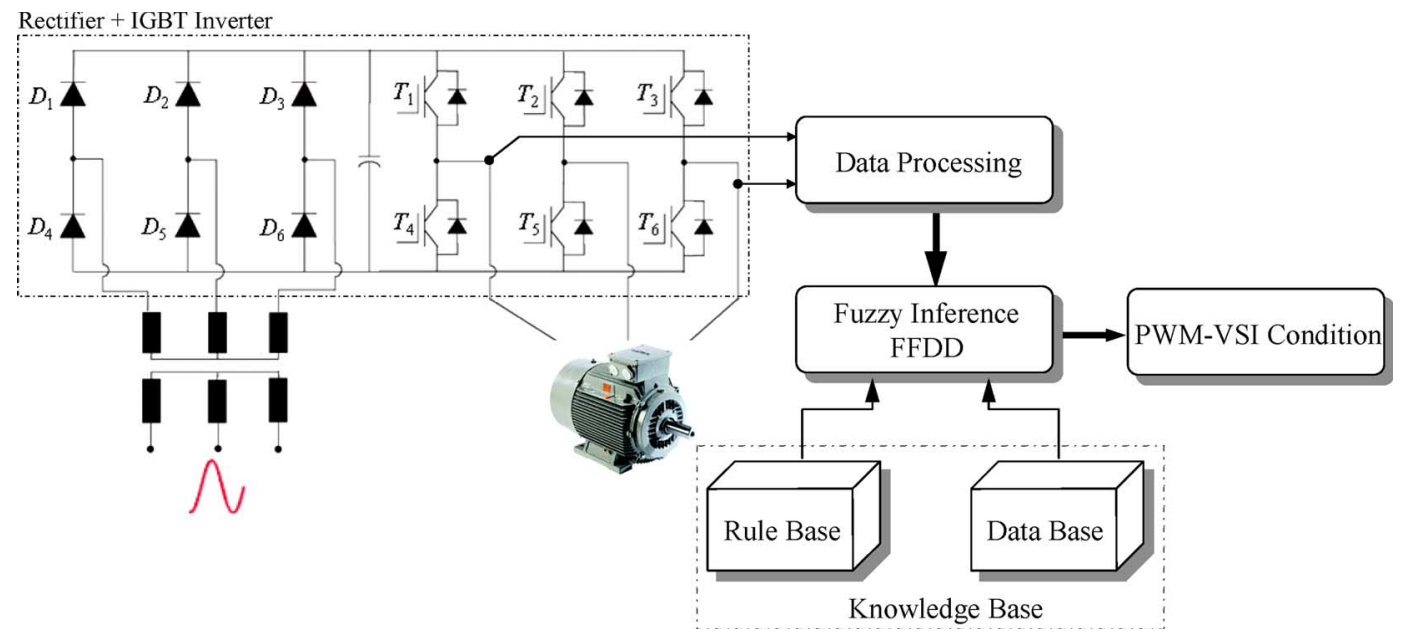

Fig. 6. Scheme of the fuzzy-based diagnosis approach.

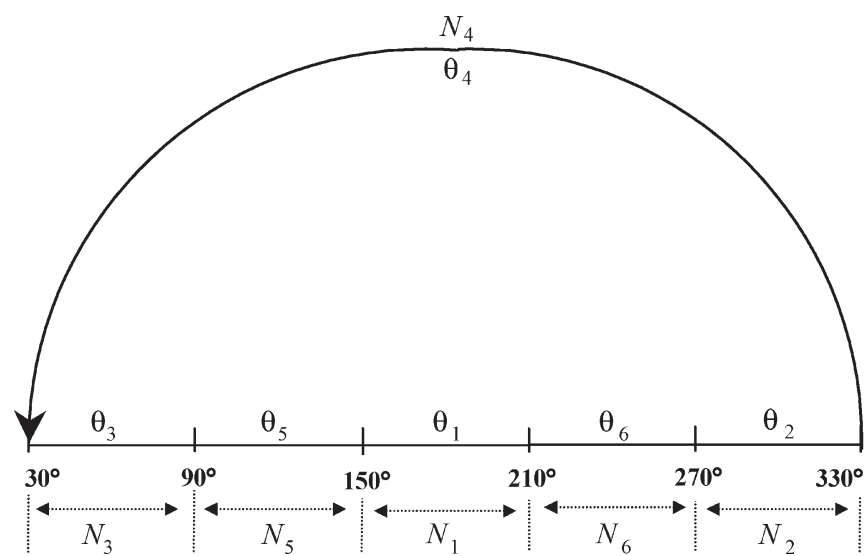

Fig. 7. Semicircle relative position according to faulty switch.

where $d_{\mathrm{H}}$ and $d_{\mathrm{F}}$ are, respectively the healthy and the faulty current pattern diameters [Fig. 5(a)]. $d_{\mathrm{H}}$ has to be well defined between zero and the minimum steady state faulty current

$$
I_{\theta}=\sum_{i=1}^{6} N_{i}
$$

where $N_{i}$ is the semicircle notation corresponding to the switch $T_{i}$ as shown by Fig. 7.

For illustration:

1) If $\theta=\theta_{1}$ the considered semicircle is $N_{1}$ and $N_{2}=$ $N_{3}=N_{4}=N_{5}=N_{6}=0$. The faulty switch is $T_{1}$.

2) If $\theta=\theta_{4}$ the considered semicircle is $N_{4}$ and $N_{1}=$ $N_{2}=N_{3}=N_{5}=N_{6}=0$. The faulty switch is $T_{4}$.

The FFDD output is the fault indicator $I_{\mathrm{DL}-\mathrm{FS}}$ (Detection/ Location of the Faulty Switch). This output can be considered as a distance indicator. If the FFDD output lies between two integer values $i$ and $i+1$, the severity level is low and the result can be interpreted as a warning. On the other hand, if the FFDD output is strictly equal to an integer value $i$, then the faulty switch is located and the severity level is high. Therefore, the FFDD output provides not only information on faulty switch detection and location but also the fault severity level as will be explained later.
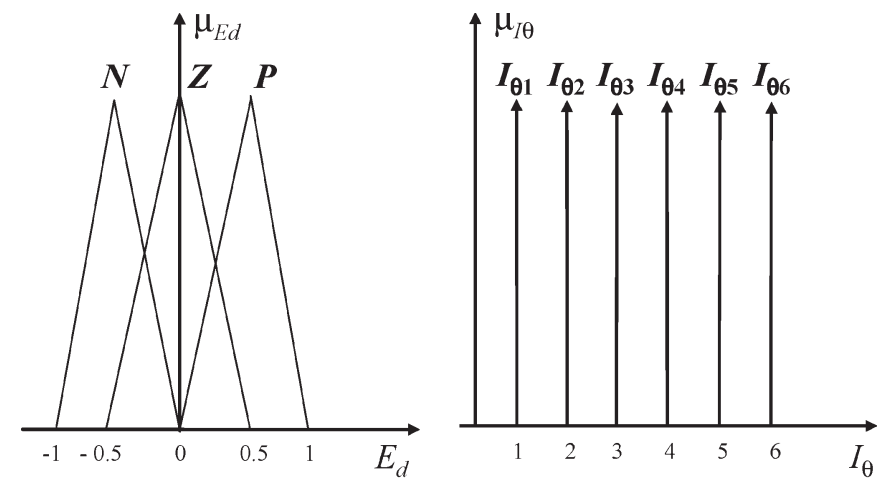

(a)

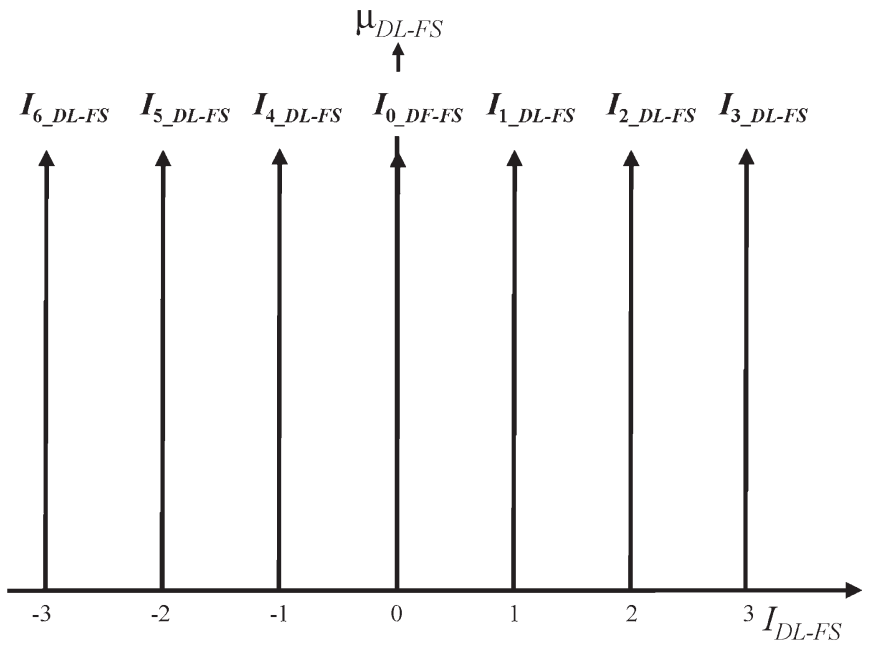

(b)

Fig. 8. FFDD membership functions. (a) Normalized input variables. (b) Normalized output variable.

\section{B. FFDD Block Design}

1) Membership Functions Selection: The input membership functions are usually a symmetric triangle with equal distribution over the universe of discourse. The formulation of membership functions of output variables show more variety frequently. The effect of choosing different output membership 
TABLE I

Linguistic Rules for the FFDD Block. ( $N$ : Negative, $Z$ : Zero, $P$ : Positive, NF: No Fault)

\begin{tabular}{|c|c|c|}
\hline$E_{d}$ & $I_{\theta}$ & $I_{D L-F S} \Rightarrow$ Faulty Switch \\
\hline$Z$ or $P$ & $I_{\theta i} ; i=1, \ldots, 6$ & $I_{0-D L-F S} \Rightarrow N F$ (No faulty switch) \\
\hline \multirow{2}{*}{$N$} & $I_{\theta 1}$ & $I_{1-D L-F S} \Rightarrow T_{1}$ \\
& $I_{\theta 2}$ & $I_{2-D L-F S} \Rightarrow T_{2}$ \\
& $I_{\theta 3}$ & $I_{3-D L-F S} \Rightarrow T_{3}$ \\
& $I_{\theta 4}$ & $I_{4-D L-F S} \Rightarrow T_{4}$ \\
& $I_{\theta 5}$ & $I_{5-D L-F S} \Rightarrow T_{5}$ \\
& $I_{\theta 6}$ & $I_{6-D L-F S} \Rightarrow T_{6}$ \\
\hline
\end{tabular}

functions like rectangle, triangle, etc., has been investigated in [25]. The formulation of the linguistic output membership functions as singletons leads to a drastic reduction of the computational effort that should be an important criterion in an online diagnosis process [26], [27]. Fig. 8 illustrates the membership functions describing the input-output variables of the FFDD block. In our case the membership functions are chosen according to the analysis given in Section II.

2) Fuzzy Rules Extraction: The list of the extracted rules is given in Table I. The extraction process consists on the following steps [27]:

1) Fuzzification: Conversion of crisp facts (inputs) into fuzzy sets described by linguistic expressions.

2) Inference: Fuzzy if-then rules express fuzzy implication relation between the premise fuzzy sets and the conclusion fuzzy sets. In our case, a Mamdani-type fuzzy inference system is used.

3) Defuzzification: Various defuzzification methods can be applied.

In our case, the system uses Max-Min composition and the centroid of area method for defuzzification.

Now, let us explain some of the extracted fuzzy rules listed in Table I. Consider the following two rules:

1) Rule 1: If $\left(E_{\mathrm{d}}\right.$ is $\left.N\right)$ and $\left(I_{\theta}\right.$ is $\left.I_{\theta 2}\right)$ then $\left(I_{2-D L-F S} \Rightarrow T_{2}\right)$.

2) Rule 2: If $\left(E_{\mathrm{d}}\right.$ is $\left.Z\right)$ and $\left(I_{\theta}\right.$ is $\left.I_{\theta 2}\right)$ then $\left(I_{0 \text {-DL-FS }} \Rightarrow\right.$ No faulty switch).

When analyzing these two cases, we notice that depending on the input values, the faulty indicator value changes. Indeed, if $\left(\mu_{\mathrm{Ed}}=0.75, \mu_{I \theta}=1\right)$ and $\left(\mu_{\mathrm{Ed}}=0.25, \mu_{I \theta}=1\right)$, then by defuzzification we obtain an output of 1.5. This can be interpreted as: the power switch $T_{2}$ may be affected by an intermittent fault (medium severity level fault). If now $\left(\mu_{\mathrm{Ed}}=1, \mu_{I \theta}=1\right)$ and $\left(\mu_{\mathrm{Ed}}=0, \mu_{I \theta}=1\right)$, then by defuzzification we obtain an output of 2. In this case, it is clear that the power switch $T_{2}$ is faulty (open circuit-high severity level fault). Fig. 9 is the FFDD

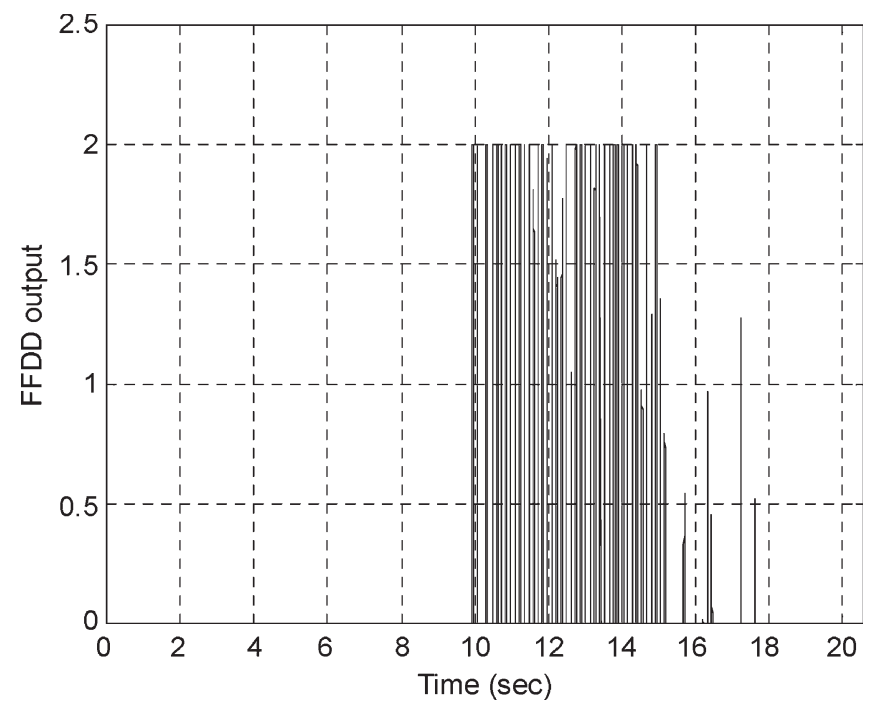

Fig. 9. FFDD output (detection of the faulty switch).

output when the pattern displayed in Fig. 3 is considered as the input. The duration is rather long which is also indicative of a severe fault on $T_{2}$.

These two examples highlight the flexibility of the approach and the key role of the input $E_{\mathrm{d}}$.

\section{EXPERIMENTS}

Fig. 10(a) describes the experimental setup. The three-phase inverter is IGBT-based with a sinus-triangle PWM in which carrier frequency is set to $1 \mathrm{kHz}$. The fault is generated by an analog circuit, which can produce a variable duration fault, a variable fault numbers per period, and a manual switch to inhibit the fault generation.

The experimental benchmark is composed of an induction motor $(1.5-\mathrm{kW}, 230 / 400 \mathrm{~V}, 3.5 / 6.10 \mathrm{~A}, 1420 \mathrm{r} / \mathrm{min})$ coupled 


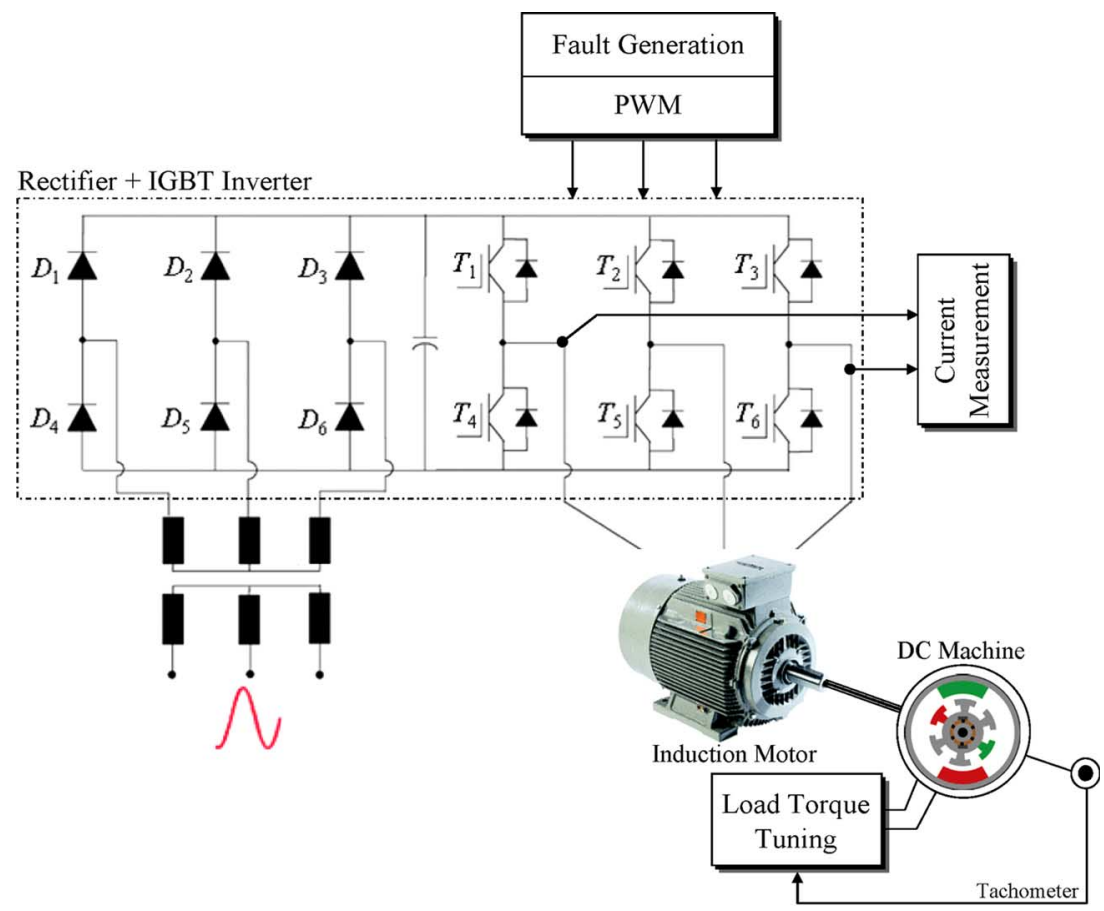

(a)

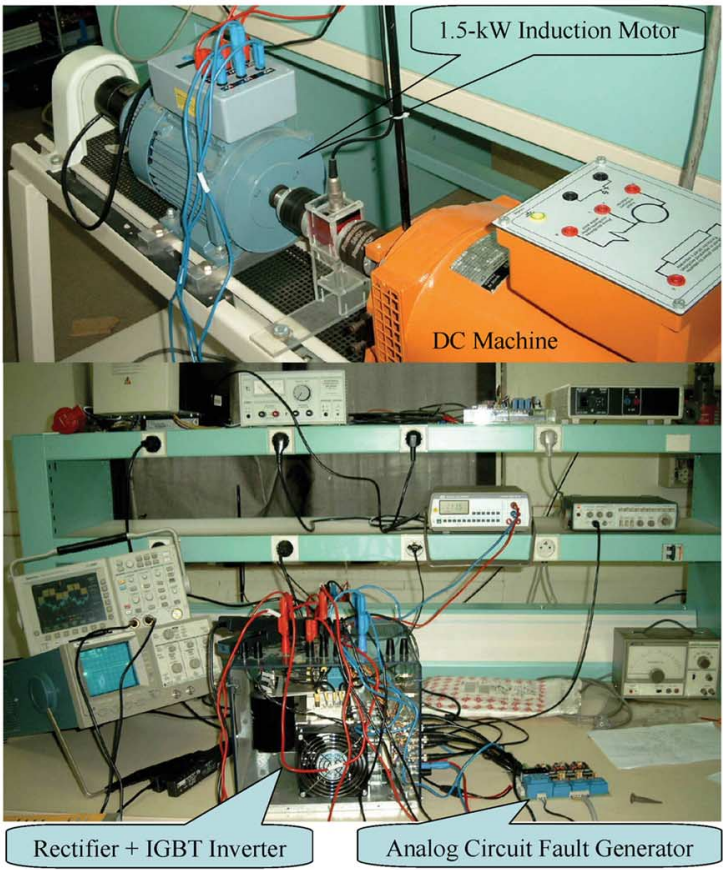

(b)

Fig. 10. Experimental setup.

to a dc machine feeding a variable resistor [Fig. 10(b)]. The misfiring time duration is adjusted to $3.5 \mathrm{~ms}$.

\section{A. Experimental Data}

Fig. 11(a) and (b) show the measured stator current waveforms for normal and faulty operations. From these currents, patterns are calculated as shown in Fig. 12 where the upper trajectory represents the healthy case and the lower one the faulty situation. The slight displacement of the current pattern reveals the intermittent fault. Compared to the normal conditions, the displacement is along the $(-\alpha)$-axis. The current pattern trajectory is then used to locate the faulty switch.

\section{B. Test of the Proposed Approach}

The experimental data are collected then treated by the proposed fuzzy approach. A result is shown in Fig. 13. The output is very close to 1 , which means that the faulty switch is $T_{1}$ with a high severity level. Small values lower than 0.5 can 


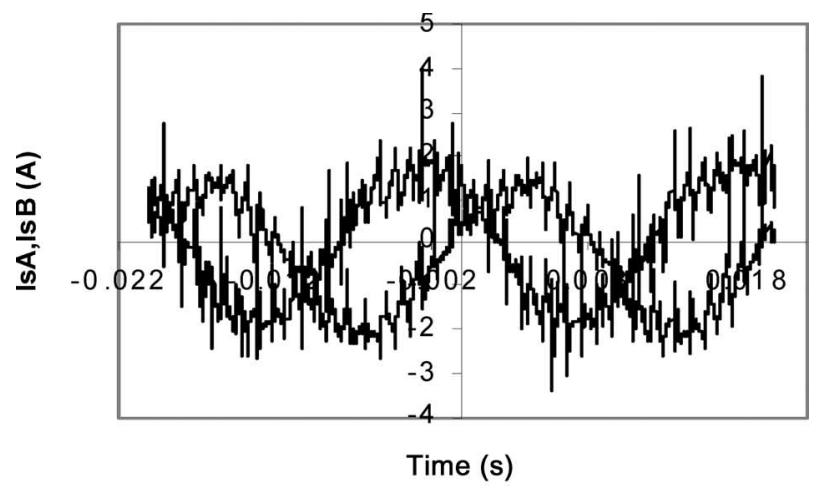

(a)

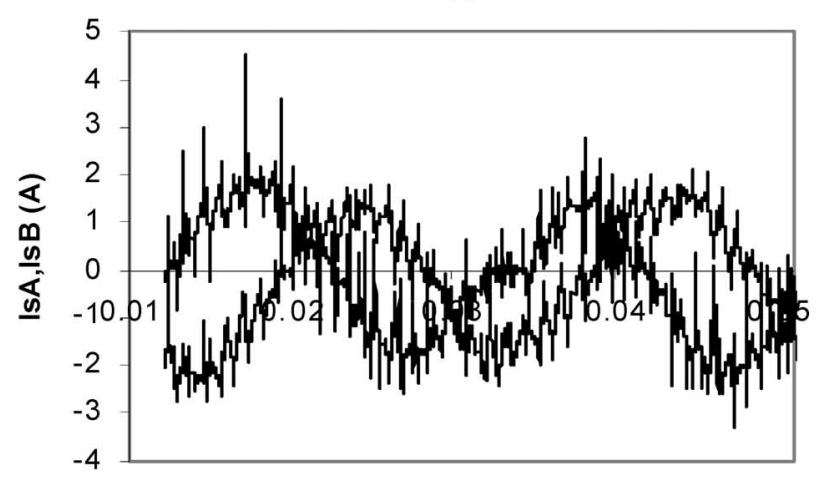

Time (s)

(b)

Fig. 11. Measured stator currents. (a) Healthy operation. (b) Faulty operation.

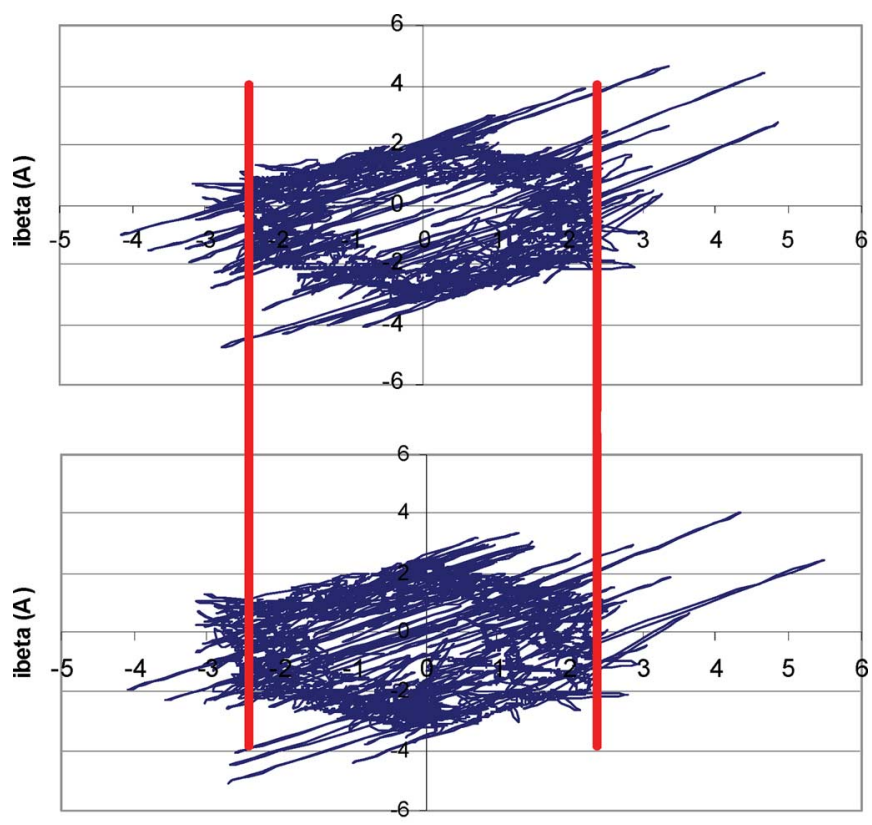

ialfa (A)

Fig. 12. Concordia current patterns.

also be seen. In fact, even in normal or healthy conditions, a slight bias always exists due to the motor natural unbalance.

As shown in Fig. 12, patterns are obviously not circles. In this case, the computation method uses a circle that encloses the

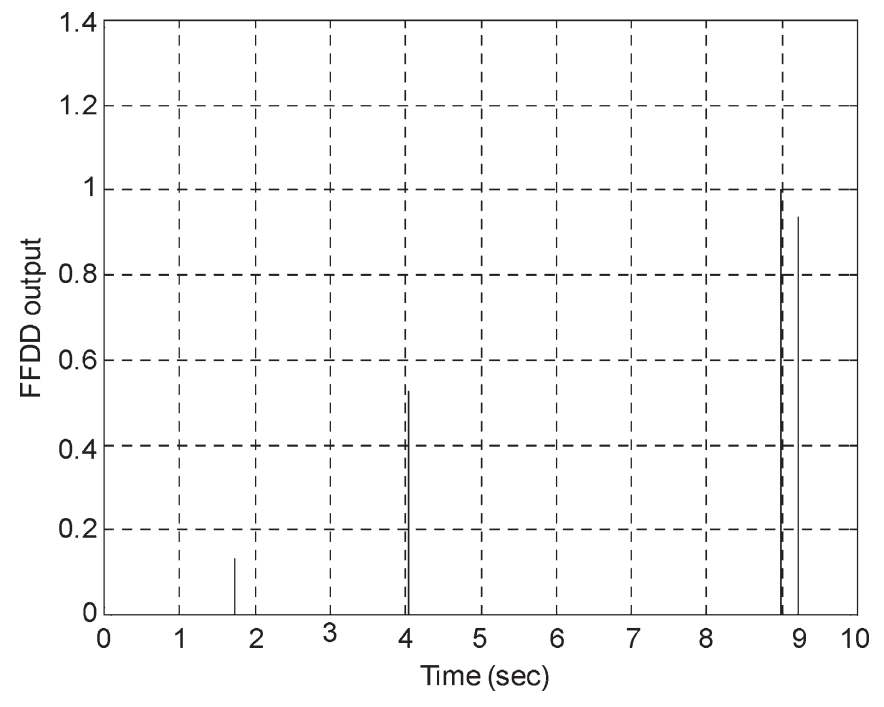

Fig. 13. FFDD output (detection of the faulty switch).

actual pattern. The healthy and faulty current pattern diameters are then easily calculated.

This test put into evidence that the FFDD is a suitable diagnosis tool to detect the occurrence of a fault in the PWMVSI feeding an induction motor.

It should be mentioned that, in a practical point of view, the proposed fault detection and diagnosis approach could not be implemented within the PWM-VSI controller. Indeed, the diagnosis task requires a higher sampling rate compared to the current controllers. Moreover, because fuzzy if-then rules are not time-consuming, an online monitoring and diagnosis process is feasible.

\section{CONCLUSION}

This paper has presented a fuzzy method for fault detection and diagnosis of switching device misfiring in a voltage-fed PWM inverter induction motor drive. The method is based on the Concordia stator current pattern. Only two current sensors are used for simplicity and cost-effectiveness purposes. In the proposed diagnosis approach, the faulty pattern is illustrated by a semicircle whose relative position indicates the faulty switch. The fuzzy diagnosis approach relies upon a diagnosis space in which Concordia current pattern deviations from the nominal operating points are computed. The appropriate selection of membership functions based on a careful insight of the drive behavior and fuzzy tuning flexibility lead to an output of the FFDD block which identifies the faulty switch but also gives the severity level. Experimental results confirm the validity of the proposed technique and clearly show that the Concordia stator current pattern together with fuzzy logic offers great potential for PWM-VSI condition monitoring.

\section{REFERENCES}

[1] A. Muetze et al., "Practical rules for assessment of inverter-induced bearing currents in inverter-fed AC motors up to $500 \mathrm{~kW}$," IEEE Trans. Ind. Electron., vol. 54, no. 3, pp. 1614-1622, Jun. 2007.

[2] F. W. Fuchs, "Some diagnosis methods for voltage source inverters in variable speed drives with induction machines. A survey," in Proc. IEEE IECON, Roanoke, VA, 2003, vol. 2, pp. 1378-1385. 
[3] R. M. Tallam et al., "A survey of methods for detection of stator-related faults in induction machines," IEEE Trans. Ind. Appl., vol. 43, no. 4, pp. 719-729, Jul./Aug. 2007.

[4] J. F. Martins et al., "Unsupervised neural-network-based algorithm for an on-line diagnosis of three-phase induction motor stator fault," IEEE Trans. Ind. Electron., vol. 54, no. 1, pp. 259-264, Feb. 2007.

[5] M. S. Ballal et al., "Adaptive neural fuzzy inference system for the detection of inter-turn insulation and bearing wear faults in induction motor," IEEE Trans. Ind. Electron., vol. 54, no. 1, pp. 250-258, Feb. 2007.

[6] S. Bachir et al., "Diagnosis by parameter estimation of stator and rotor faults occurring in induction machines," IEEE Trans. Ind. Electron., vol. 53, no. 3, pp. 963-973, Jun. 2006.

[7] J. H. Jung et al., "Online diagnosis of induction motors using MCSA," IEEE Trans. Ind. Electron., vol. 53, no. 6, pp. 1842-1852, Dec. 2006.

[8] M. E. H. Benbouzid et al., "What stator current processing based technique to use for induction motor rotor faults diagnosis?" IEEE Trans. Energy Convers., vol. 18, no. 2, pp 238-244, Jun. 2003

[9] D. Kastha et al., "Investigation of fault modes of voltage-fed inverter system for induction motor drive," IEEE Trans. Ind. Appl., vol. 30, no. 4, pp. 426-433, Jul./Aug. 1994.

[10] K. S. Smith et al., "Real-time detection of intermittent misfiring in a voltage-fed PWM inverter induction-motor drive," IEEE Trans. Ind. Electron., vol. 44, no. 4, pp. 468-476, Aug. 1997.

[11] R. Peuget et al., "Fault detection and isolation on a PWM inverter by knowledge-based model," IEEE Trans. Ind. Appl., vol. 34, no. 6, pp. 1318-1326, Nov./Dec. 1998.

[12] A. M. S. Mendes et al., "Voltage source inverter fault diagnosis in variable speed AC drives, by the average current Park's vector approach," in Proc. IEEE IEMDC, Seattle, WA, 1999, pp. 704-706.

[13] C. Kral et al., "Power electronics monitoring for a controlled voltage source inverter drive with induction machines," in Proc. IEEE PESC, Galway, Ireland, 2000, vol. 1, pp. 213-217.

[14] S. Abramik et al., "A diagnostic method for on-line fault detection and localization in VSI-fed AC drives," in Proc. EPE, Toulouse, France, 2003.

[15] K. Rothenhagen et al., "Performance of diagnosis methods for IGBT open circuit faults in voltage source active rectifiers," in Proc. IEEE PESC, Aachen, Germany, 2004, vol. 6, pp. 4348-4354.

[16] R. L. D. A. Ribeiro et al., "Fault detection of open-switch damage in voltage-fed PWM motor drive systems," IEEE Trans. Power Electron., vol. 18 , no. 2, pp. 587-593, Mar. 2003.

[17] M. S. Khanniche et al., "Wavelet-fuzzy-based algorithm for condition monitoring of voltage source inverter," Electron. Lett., vol. 40, no. 4, pp. 267-268, Feb. 2004.

[18] P. Gilreath et al., "A new centroid based fault detection method for 3-phase inverter-fed induction motors," in Proc. IEEE PESC, Recife, Brazil, 2005, pp. 2664-2669.

[19] K. Debebe et al., "Expert systems for fault diagnosis of VSI fed AC drives," in Conf. Rec. IAS Annu. Meeting, Dearborn, MI, 1991, vol. 1, pp. 368-373.

[20] S. Khomfoi et al., "Fault diagnostic system for a multilevel inverter using a neural network," IEEE Trans. Power Electron., vol. 22, no. 3, pp. 10621069, May 2007.

[21] Y. L. Murphey et al., "Model-based fault diagnosis in electric drives using machine learning," IEEE/ASME Trans. Mechatronics, vol. 11, no. 3, pp. 290-303, Jun. 2006.

[22] M. E. H. Benbouzid et al., "Induction motor stator faults diagnosis by a current Concordia pattern based fuzzy decision system," IEEE Trans. Energy Convers., vol. 18, no. 4, pp. 469-475, Dec. 2003.

[23] M. E. H. Benbouzid et al., "Monitoring and diagnosis of induction motors electrical faults using a current Park's vector pattern learning approach," IEEE Trans. Ind. Appl., vol. 36, no. 3, pp. 730-735, May/ Jun. 2000

[24] D. Diallo et al., "Fault detection and diagnosis in an induction machine drive: A pattern recognition approach based on Concordia stator mean current vector," IEEE Trans. Energy Convers., vol. 20, no. 3, pp. 512519, Sep. 2005.

[25] R. Isermann, "On fuzzy logic application for automatic control, supervision, and fault diagnosis," IEEE Trans. Syst., Man, Cybern. A, Syst., Humans, vol. 28, no. 2, pp. 221-235, Mar. 1998.

[26] M. Y. Chow, Methodologies of Using Neural Network and Fuzzy Logic Technologies for Motor Incipient Fault Detection. Singapore: World Scientific, 1997.

[27] M. Y. Chow et al., "Intelligent Motor Fault Detection," in Intelligent Techniques in Industry, L. C. Jain, Ed. Boca Raton, FL: CRC Press, 1998.

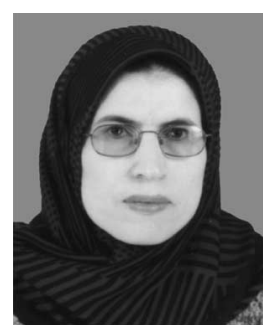

Fatiha Zidani was born in Batna, Algeria, in 1968. She received the B.Sc., M.Sc., and Ph.D. degrees in electrical engineering from the University of Batna, Batna, in 1993, 1996, and 2003, respectively.

After graduation, she joined the University of Batna, where she is an Associate Professor in the Electrical Engineering Department. She is with the Laboratoire des Systèmes de Propulsion et Induction Electromagnétique of the University of Batna. Her current area of research includes advanced control techniques and diagnosis of electric machines and drives.

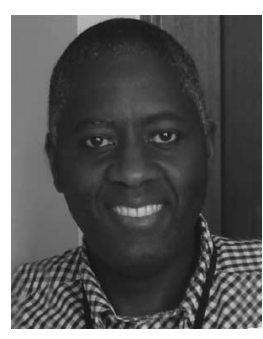

Demba Diallo (M'99-SM'05) was born in Dakar, Senegal, in 1966. He received the M.Sc. and Ph.D degrees in electrical and computer engineering from the National Polytechnic Institute of Grenoble, Grenoble Cedex 1, France, in 1990 and 1993, respectively, and the "Habilitation à Diriger des Recherches" degree from the University of Paris Sud P11, Orsay, France, in 2005.

From 1994 to 1999, he worked as a Research Engineer in the Laboratoire d'Electrotechnique de Grenoble, Saint Martin d'Hères, France, on electrical drives and active filters (hardware and software). In 1999, he joined the University of Picardie "Jules Verne," Amiens Cedex, France, as Associate Professor of electrical engineering. In September 2004, he joined the University Institute of Technology of Cachan, University of Paris Sud P11, as an Associate Professor of electrical engineering. He is with the Laboratoire de Génie Electrique de Paris, Gif-sur-Yvette Cedex, France. His current area of research includes advanced control techniques and diagnosis in the field of ac drives.

Dr. Diallo is a Senior Member of the IEEE Industry Applications, Vehicular Technology and Control Systems Societies. He is an Associate Editor of the IEEE TRANSACTIONS ON Vehicular TEChNOLOGy.

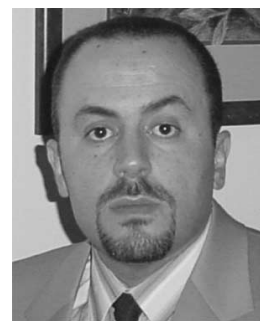

Mohamed El Hachemi Benbouzid (S'92-M'95SM'98) was born in Batna, Algeria, in 1968. He received the B.Sc. degree in electrical engineering from the University of Batna, Batna, in 1990, the M.Sc. and Ph.D. degrees in electrical and computer engineering from the National Polytechnic Institute of Grenoble, Grenoble, France, in 1991 and 1994, respectively, and the Habilitation à Diriger des Recherches degree from the University of Picardie "Jules Verne," Amiens Cedex, France, in 2000.

After receiving the Ph.D. degree, he joined the Professional Institute of Amiens, University of Picardie "Jules Verne," where he was an Associate Professor of electrical and computer engineering. In September 2004, he joined the University Institute of Technology of Brest, University of Western Brittany, Brest, France, as a Professor of electrical engineering. His main research interests and experience include analysis, design, and control of electric machines, variable-speed drives for traction and propulsion applications, and fault diagnosis of electric machines.

Dr. Benbouzid is a Senior Member of the IEEE Power Engineering, Industrial Electronics, Industry Applications, Power Electronics, and Vehicular Technology Societies. He is an Associate Editor of the IEEE TRANSACTIONS ON ENERGY CONVERSION, the IEEE TRANSACTIONS ON INDUSTRIAL ELECTRONICS, the IEEE TRANSACTIONS ON VEHICUlar TECHNOLOGY, and the IEEE/ASME TRANSACTIONS ON MECHATRONICS.

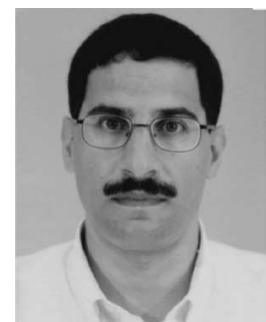

Rachid Naït-Saïd was born in Batna, Algeria, in 1966. He received the B.Sc., M.Sc., Ph.D., and "Habilitation Universitaire" degrees in health and safety engineering from the University of Batna, Batna, in 1990, 1996, 2004, and 2005, respectively.

After graduation, he joined the University of Batna, where he is an Associate Professor in the Health and Safety Engineering Institute. He is with the Laboratoire des Systèmes de Propulsion et Induction Electromagnétique of the University of Batna. His current research interests include the application of fuzzy logic to risk assessment and diagnosis. 